\title{
Corrigendum: Nod2-mediated recognition of the microbiota is critical for mucosal adjuvant activity of cholera toxin
}

Donghyun Kim, Yun-Gi Kim, Sang-Uk Seo, Dong-Jae Kim, Nobuhiko Kamada, Dave Prescott, Dana J Philpott, Philip Rosenstiel, Naohiro Inohara \& Gabriel Núñez

Nat. Med. 22, 524-530 (2016); published online 11 April 2016; corrected after print 26 May 2016

In the version of this article initially published, Mathias Chamaillard was inadvertently omitted from the list of authors and from the Author Contributions section. The error has been corrected in the HTML and PDF versions of the article. 